\title{
Migration as a Challenge for Albanian Post Communist Society
}

\section{Ph.D Cand. Matilda Likaj}

\author{
Department of Educational Sciences, Faculty of Educational \& Philology \\ Bedër University, Tirana, Albania \\ e-mail: matildalikaj@gmail.com
}

\section{Doi:10.5901/jesr.2014.v4n2p143}

\begin{abstract}
Migration is a global phenomenon caused not only by economic factor but many others like social, political, cultural, environmental, health, education etc. It generally takes place from the area of less economic opportunities and retarded social development towards developed and fast developing areas. But in Albania this phenomena was quite different from the other society. By the end of stricter communism regime and the raise of democratization process in Albania, brought out huge challenges for Albanian society. One of these challenges was the movement of people as the cause of internal and international migration phenomena. The 'open border' toward all countries in the world, especially toward Western ones during 1990's was a quite new phenomena for Albanian society, that cause drastic, rapid, inevitable and unplanned changes in the population. This happened as the result of many reasons. Such as the forbidden of moving outside Albania and the curiosity of 'what is around' was one of reasons to migrate. Also, forbidden of movement of people for continuing their life, within Albania were as push factor to form the internal migration. Although economical, political, education and socio-cultural beneficiaries were some of push factors for internal and international migration in Albania. The objectives of this articles are going to be focus on analyze of internal and international Albanian migration during post communist period till nowadays. During analyze of this phenomena is going to take into consideration social changes, social capital and its effect on the Albanian society challenges.
\end{abstract}

Keywords: Migration Phenomena; Social changes; Social Capital; Albanian Post Communist Society

\section{Introduction}

The collapse of communism in the Balkans brought about significant political, economical and socio-cultural changes. Albania was one of the countries influenced by these changes, which became internationally pluralist country after establishing of the democratic political system. During 1990-s the end of the communist regime and the raise of democratization process helped Albanian society to become 'open border' toward other countries of the world, especially toward Western countries. This situation formed the contact of Albanian state with other states in the world. This phenomenon was quite new and had complex consequences of the Albanian society. The transition process occurred during a period of economic and political unrest and led to social and demographic changes accompanied by large flows of people within and out of the country. This process, which has been characterized by economic and political unrest, led to social and demographic changes accompanied by large flows of people within and out of Albania. Massive exodus occurred over this period, mainly to the neighbouring countries such as Greece and Italy. This was a stereotype exodus incomparable with any of the other former communist countries. 'The most visible exoduses were in July, 1990, when several thousand Albanians took refuge in foreign embassies in Tirana, and from March to August, 1991, when boats almost submerged by dense crowds of shabbily dressed Albanians, crossed the Adriatic to Italy. Over the same period thousands of Albanians walked across the mountains from southern Albania into northern Greece' (De Waal; 6).

The process of migration, both internal and international one, has increasingly been seen as involving economic, political and demographic changes, as well as processes of urbanization and modernization. Migration has profound social, cultural and economic consequences for individuals, families, communities, society, regions and the country as a whole. The effect of migration is reflected in the population decreasing and the massive urbanization of some areas and de-urbanization of others, increased differentiations among social and economical stratifications that reflect to the integration of migrants, dynamic changes in the gender and the age or demography of the population. So this reflects to the dynamic changes within a society. The process of migration, both the internal and international one, has increasingly been seen as involving economic, political and demographic changes as well as processes of urbanization and modernization in Albania. Migration has profound social, cultural and economic consequences for individuals, families, 
communities, society, regions and the country as a whole. The role of migration is reflected in young and middle age population decreasing and in the massive urbanization of some areas and de-urbanization of others, as well as a decrease in the population of rural regions. This period increased social and economical stratifications of urban areas relatively with integration of migrants, social and cultural transformation of the regions, brought about changes in dynamism of the age structure of the population. Therefore, it is very important to point out that migration has been one the most dynamic features of the Albanian transition. In this article it is going to be analyzing migration phenomena and its challenges in home society. Also this article discusses Albanian migration phenomena and analyzes its effects of social changes and social capital in society.

\section{Migration Phenomena and its Challenges in Home Society}

Migration all over the world is the excepted as documented or undocumented people movement, which are effected by political incorporation, economics, politics or historical associations. Until relatively recently, there were few scholars working on migration phenomena and its issues. However the number of contemporary studies had been increased by the fact that any research on immigration almost certainly flows over disciplinary boundaries. By the beginning of the $21^{\text {st }}$ century, international population movements had evolved into five discernible migratory systems, each one characterized by a rough stability of migrant flows across time and space. 'In general, the flows of people within these systems parallel flows of goods, capital, and information that are partially structured by international politics' (Massey; 15).

Migration is a very complex phenomena in the perspective of socio-cultural and economic life. Human migration is the movement of people from one country to another for the purpose of taking up permanent or semi permanent residence, usually across a political boundary. For thousands of years people have migrate to search for food, survive conquer frontiers, colonize new territories, escape from war zone or political authorities and look for new and more rewarding and existing opportunities. People can either choose to move or voluntary migration and be forced to move or involuntary migration. According to a widely used definition, migrants are persons who have been outside their country of birth or citizenship for a long period of time and stay there for different reasons. On the migrant side, one can usefully distinguish three main groups: economic, forced and family migrants, which is a distinction based on the motivations for leaving one's country of origin. According to me, migrants could not be classified on just three groups because there are so many people who are not forced to migrate but they want to leave their countries for political reason (such as political transition), for education and for a better socio-cultural activities. Engle claimed that migration is often cast as a "problem" to "control" in the domestic politics of richer countries, heightened by recent concerns with "national security' (Engle; 25). Also in social sciences, the term 'migrant' spread an underlying definitional imprecision that blurs the respective fields of study, socio-cultural and policy-making as well as the linkages between these. So we can claim that migration is the moving of people internally within countries, or internationally between countries from sending to receiving countries. This moving may be for the short or long term, for economic, political, cultural or social reasons. It may be regular/legal or irregular/illegal. 'Migration all over the world is the excepted as documented or undocumented people movement, which are effected by political incorporation, economics, politics or historical associations. But unfortunately the prevailing approach of national policymakers is accordingly one of managing the flow of migrants (Lucas; 71) driven by domestic concerns rather than more global interests or the interests and rights of migrants. The intergovernmental body, the International Organization for Migration (IOM), works under the banner of 'Managing migration for the benefit of all' and has gained significant support from governments (Jolly \& Bridge; 29).

Ravenstein saw migration as an inseparable part of development, and he asserted that the major causes of migration were economic. Migration patterns were further assumed to be influenced by factors such as distance and population densities. According to Hein people are expected to move from low income to high income areas, and from densely to sparsely populated areas, that is, the general notion that migration movements tend towards a certain spatialeconomic equilibrium, has remained alive in the work of many demographers, geographers, and economists ever since and, as we will see, is also the underlying assumption of push-pull theories (Hein; 4).

Different theories of migration (such as Push and Pull Theory; Neo-Classical Equilibrium theory; Historical Structural Theory; Transnational Migration Theory etc), which mainly focus on the causes of migration and the feedback mechanisms through which population movements, are perpetuated. So the causes and consequences of migration are strongly interrelated, and part of the same general processes of social and economic transformation, the circumstances that cause migration will equally affect migration on development in sending societies. For this reason we can say that migration phenomena's complexity can be seen also to definitions above. And the complexity is multidimensional and varies according to migration flood/wave each society. 
The scholarly debate has tended to separate the developmental determinants and effects or impacts of migration artificially from more general processes of social including economic change. There is a clear need to study migration impacts in their wider societal context, and to see how migration as: A process which is an integral part of broader transformation processes embodied in the term "development"; but also has its internal, self-sustaining and selfundermining dynamics; and impacts on such transformation processes in its own right (Hein; 2). So, is very important to say that emigration play a very important role not just for reorganization of life, but for society's cultural, social, economical and political perspective.

The complexity of migration trends in the twenty-first century cannot be ignored. In the past, most migrants came from countries with colonial and specific bilateral arrangements to European and other economical development countries. But the migration profile has been changed during the last decade. There has been a rapid increase in the diversity of migrants as a result of a more interconnected world, with continued economic disparities. The increase in the number of sending countries has resulted in a new 'super-diversity' in Europe, with many disparate communities composed of small groups made up of many different nationalities. So consequently to this we can claim the other face of complexity of migration phenomena. The flow of migrants to Europe has also become more complex in terms of movement and legal status. After the fall of communism and the opening of borders of Albanian state, another factor affected the rise of migrations flows. This factor was and still is globalization. Globalization is changing the nature of the migration journey.

According to Hans de Hein, one-way voyages to a new country of settlement, the type of migration which populated the New World, are giving way to more temporary and flexible movements, and a new generation of migrant globetrotters. With cheaper communication and travel, migrants have greater opportunities to maintain links with their home-countries, and 'return' and 'circular' migration is becoming increasingly commonplace. In Europe particularly, an increasing proportion of the migrant population is 'transnational: that is to say, people working in one country while maintaining a family and social life in another (Hein; 26). According to this perspective is very evident and important to say that the problematic form of migration is reflected to the social relation of one society. So migration is very benefit for the economical conditions but its reflection or symptoms causes the social anomies for receive and hosted societies too. This phenomenon is seen in social identities of migrants, such as they have e feeling of not belonging in the hosted society but even in their own state. So this feeling is mostly related with integration according to policies of receive countries and sometimes this application may not be totally voluntary.

Migration phenomena's complexity derives from a number of factors. According to Vullnetari these factors may include origin or destination country perspectives, macro or micro analyses, discipline based approaches, concerns over short or long term impacts, varying types of migration and development spatially and over time and, not least, various ways of measuring the two. (Vullnetari;35). Increasing interdependencies of social, economic and political aspects require an approach that takes these global interdependencies into account, but also embeds the analysis in a specific social and geo-historical context relevant to the study. So as conclusion it is very important to say that, migration is a complex phenomena that appears with multi-dimensions in society.

\section{Albanian Migration: Its Effects on Social Changes and Social Capital in Society}

\subsection{Albanian Migration and Social Changes}

Migration, whether rural to urban or international, has emerged as the most common livelihood coping strategy in Albania, and has served as an important escape valve for unemployment and other economic difficulties brought on by the transition to a market economy. 'Driven by these dire economic conditions, and facilitated by geographical proximity and the lure of Western affluence transmitted through Italian television channels' (Ma; 7), many Albanian households perceived migration, whether temporary or permanent, as an effective strategy for sustaining and improving their economic livelihoods. This view was amply reflected in the government's complacent position towards emigration, which was seen, at least initially, as a means of exporting unemployment and importing wealth ( Azzarri\& Carletto; 2)

According to sociological view of migration, it is very important to say that, Albanian migration phenomena has an extremely dynamic nature, the main objective of this paper is to analyze and understand Albanian migration and its effects on social changes and social capital of the society. Overall, migration in Albania continues to be a very dynamic and all-pervasive phenomenon, with the majority of Albanian households having experienced some form of migration since 1990 and one third of households having at least one split-off household member currently living abroad. Striking changes in both the magnitude and composition of the flows are still occurring at an impressive pace, with new patterns 
emerging over the past few years, and old patterns stabilizing or transforming, in response to changing conditions in the main host countries and as part of a natural maturation of the migration process.

The migration process has been dynamic over two decades in Albanian. For example the outflows following the collapse of the pyramid saving scheme in late 1996, international migration appears to be tapering off. Although migration is likely to continue at a sustained level for years to come at least as long as economic differential remains with the neighboring countries it is obvious that the outbreak of domestic crises and sudden shocks have been behind the two large migration epochs over the past 20 years. Also the reflections of migration flows in Albanian society has been effected its structure and its social capital. As pointed out, the flow of migration effects the socio-demographic characteristics of migrants have been changing over time. The movement of people in and out of Albanian has been effect the structure of society. A new organization of society has been caused many social problems and new social phenomena in Albanian society.

An important element to be taken into consideration is also the suggesting an overall deterioration of the humancapital quality of more recent flows: less educated and older migrants appear more likely to migrate in recent years, in addition to an ever-increasing number of women (however the latter have higher educational levels, on average, than men). Excluded from these patterns is migration to destinations other than Greece and Italy. These other destinations continue to attract better educated and potentially more productive migrants, mostly from Tirana and other large cities. Thus, two clear flows emerge, with increasingly less educated migrants from rural areas seeking a better life in Greece and Italy, and more educated urban dwellers, often female, migrating to farther destinations in European countries, America, and all over the world. Also, not surprisingly, the unstable economic situation and sudden shocks have created stronger push factors at different points in time, resulting in larger numbers of less-suitable individuals taking the migration path.' However, as reflected in the trends and composition of the flows of returnees, these less endowed migrants are also more likely to return, and to return sooner. As confirmed by the ALSMS data for 2005, returnees are on average worse-off than permanent migrants and the likely stairs' ( Azzarri\& Carletto; 24).

The movement of Albanian social actors within and outside the country has been one or the most important factor of the dynamic of society. The direction of migratory flows depends mainly on social, economic and cultural factors, on the change of social structure and on new perspectives of social life. It is important to state that migration is, in general, not solely individual decision, but also most frequently a phenomenon that takes place in a family context. One or two members of the family migrate while the others stay in their home country. This phenomenon can be observed also with respect to the Albanian migration.

The role of migration is reflected in the population decreasing and the massive urbanization of some areas and deurbanization of others, increased social and economic stratifications of urban areas related to the integration of migrants, social and cultural transformation of the regions, changes in the gender and the age structure of the population and even the dynamics of social changes. The situation of overpopulation or depopulation has been caused the reorganization of society structure based on these demographic inequalities. The transition process in Albania reflects, for the most part, 'society depression'. This means that social institutions are not functioning well. For examples Albanian families in which one or two member are migrants, appear to have different social problems. From the effect of these social problems it may be called as 'depressively' situation of family. Therefore, when one parent migrates, the other (that could meet the partner after a very long period of time and could not participate as an active family member in family life) has to play both social roles as father and mother. This situation has anomic impact on children and even on the parents themselves. Also it may be identified as a situation that causes the social and personal identity anomies. But on other hand, it is important to stress that remittances sent by the migrants help to maintain the family's economic life and also increase the inputs into the Albanian economy as a whole. As a conclusion it is important to stress that migration has been one the most dynamic features and very complex phenomena for the Albanian transition.

The flow of young people as a work force outside Albania forms the lack of population dynamism and anomies in socio cultural structure of Albania. The anomies reflect also in social cohesion and development of society. Extremely demographic changes loose the focusing on control of population in home country. But another dynamic that reflect on the positive manner is the economic growth and prosperity from the remittances of migrants. This makes possible the country development and also has social and economic impacts. These impacts bring out the national growth and development and also the political stabilization. So it is important to stress those migration phenomena of Albanian society brought out positive and negative social changes from its dynamical structure.

Another challenges stem from migration's impact on the reorganization of social structure. The flow of young people as a work force outside Albania leads to the lack of population dynamism and anomies in the socio-cultural structure of Albania. The anomies are reflected also in the social cohesion and development of society. But also, on other 
hand, migration has a positive impact on the economic growth and prosperity, due to remittances of migrants. This enables the country's development and also has social and economic impacts. These impacts bring about the national growth and development and also political stabilization. So it is important to stress that migration in the Albanian society brought about both positive and negative changes in its dynamical structure.

\subsection{Albanian Migration and Social capital}

Social capital has been treated as one of the most important topic in recent years in social sciences and has many theories about it. The reason why this term has been so much study is that social capital contents elements of social life (which are numerous) and elements of culture, economy, politics etc. Even the sociological study of social capital is plentiful in number and dimensions. "Besides links the individual with family and kin (tribe) creates individual links to various individuals and groups to facilitate social life but also to continue the daily social life (Aydemir; 97). This occurs not only because of dynamics of sociology as a science but also of social dynamics and diversity in social and cultural elements. These elements have been identified by as the social truth by Bourdieu. One of these elements is the phenomena of emigration and integration of emigrants in host societies. Boudieu in 'Forms of capital' book, states that social capital is formed of three main resources that are economic, cultural and social. (Bourdieu; 3). For Coleman, social capital is a major way to understand the link between social environment, cultural and individual contributions (Coleman; 120). Further arguments Coleman social capital has focused on taking into account the resource group that is present in family ties and social organization of society. These reflect the socialization and education of children in the family and social environment (Coleman; 45). Putman considers social capital as 'networks / network, norms and trust' that enable the participation of individuals in a community (Putnam; 66). Gould considers cultural capital as an important part of social capital, which means that when a community gathers under cultural elements (celebrations, rituals, intercultural dialogues, etc.) add / strengthen ties, co-participation and networks (Gould; 69).

In the broader sense, the social connections to social capital, displayed a power potential that can be activated at any time to achieve common objectives and expectations of society. Social ties represent huge potential to build social capital for social structure, form the link between social institutions consistently have the ability to build and rebuild social values, have the operational capability to form the principles of legality of reciprocity between individuals and solidarity to enable collaboration and individual consultation. 'In some way you can rephrase social potential as a key element in the construction of shared social identity and tonic connections between the individual and the community' (Aydemir; Tecim; Likaj; 7).

In other words, social capital is building connections between individuals and the community, which focuses on the formation of connections based on trust between the people and strengthening the social construction of community and society. Social capital functions based on: individual skills, knowledge and abilities of building links and social networking groups. Putman, explains social capital contains 'elements of social organization such as trust, norms and nets' that improve the efficiency of society by facilitating interaction action. (Putnam; 167)

Figure 1: Components of social capital (Cherti; 44)

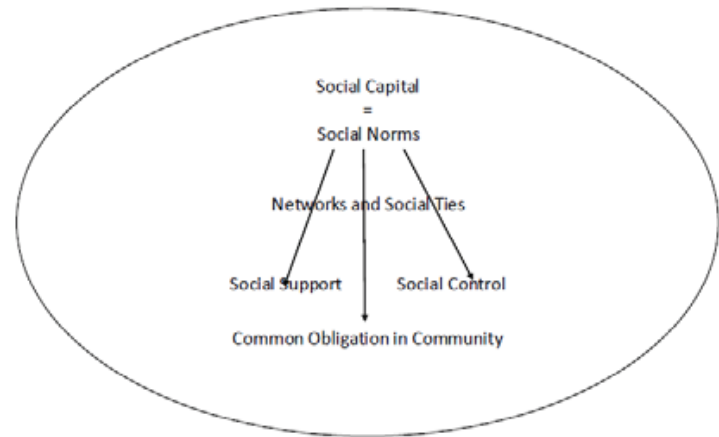

According to above figure, the main components of social capital and social network are connections, support and social control, joint obligations. All these rates in component form social networks that 'are catalyst' for social interactions on the same network. Also one other important element is 'trust'. 'Faith' corporate at all levels of social norms, in fluctuations that may incur society. Faith is dependent on the type of network and the nature of the development of links within these 
networks. So in short we can say that social capital is multi-dimensional functions of its interdependent elements leading to the continuation of solidarity in a society. According to the sociological approach to the individual choice to emigration emphasizes the relevance of certain factors, such as social organization, especially the networks of knowledge and family links that can be found in the migratory chain (Venturini, 2004; 13). But this issue sometimes may influence the fade of faith in social environment.

Although, analyze of social capital in Albanian society by taking into consideration the migration phenomena, is very important to claim that there are huge anomies on its application in everyday life. In Albanian society, social capital takes a very important place, but in its application have been seen very absences of this structure. By the migration of many people (especially some person from one family) and by the movement of people from one region to another one (especially from rural region toward urban region) social network connection are fading, social control is very low and social support is not applicable. The element of faith, most of the time could not be taken into consideration. Also, after migrating to form the social ties is not so easy. Social ties have a huge potential to build social capital for social structure, form the link between social institutions consistently have the ability to build and reconstruct social values. Migrants from social ties according to feeling of 'belonging' to some culture's or same origin's group. All these issues appear the fade of social capital and its problematic situation caused by migration phenomena in Albanian society.

Social capital, in the form of strong social ties and kinship, facilitates the migration of members of the group. Especially, in relatively poor societies where social events and beliefs are usually based on tribal ties and social capital 'connector' (bonding). These links are the primary source to achieve access / connectivity on international migration. 'This connection enables national immigration through marriage, for providing information and assistance finding housing and work etc. Often migrants and their children, prefer to marry a partner of their country with the same ethnic origin and sometimes even from the same location (town or village)' (Hein;15). Society is a structure consisting of values and social relations of mutual. So is important to note that the study of common principles of life becomes inevitable. One of common bases of some society is social capital as an important element of social structure, its implications in everyday life and values, norms and traditions that form the lifestyle in the society. 'These important elements such as values, norms, social institutions, traditions and behaviors form the basis of social connections. These elements give life to a society (Aydemir, 2011: 75). Different elements form the diversity within a society, such as the migrant's social and cultural background. Also these elements change by the inputs and outputs that migration phenomena influence in social structure.

\section{Conclusion}

Migration (in and out of Albania) involves a series of events that can be challenge for society. Sometimes, the process involves uprooting, being separated from traditional values, being placed in new social and cultural different situations of society. Also these changes may be appearing in the huge social changes and the fade of social capital of social structure.

Migration phenomena impact s also on the reorganization of social structure. The flow of young people as a work force outside Albania leads to the lack of population dynamism and anomies in the socio-cultural structure of Albania. The anomies are reflected also in the social cohesion and development of society. The social changes come out of migration phenomena reflect and effect the family structure too.

Another important element of social structure of a society is social capital. In this study the social capital takes a very important place during analyzing of migration phenomena. For this reason is not wrong if it may be claimed that its application have been seen very absences of this structure. By the migration of many people (especially some person from one family) and by the movement of people from one region to another one (especially from rural region toward urban region) social network connection are fading, social control is very low and social support is not applicable. As conclusion, is very important to stress that migration phenomena has caused the drastic social changes in Albanian society and had been reversed the social capital according to the anomic situation that have been appeared.

\section{References}

Aydemir M. A.; Tecim, E. \& Likaj, M. (2012), Potenciali i Familjes dhe Fesë Te Kapitali Social i Shoqërisë Turke, Lente Sociologjike, Issue 2, Tirane.

Aydemir, M. A. (2011). Sosyal Sermaye: Topluluk Duygusu ve Sosyal Sermaye Arastirmasi. Konya. Cizgi kitap evi yayinlari,

Bourdieu, P. (1980), 'Capital social. Notes provisoires', Actes de la Recherche en Sciences

Carlo Azzarri, Calogero Carletto; (2009). Modeling Migration Dynamics in Albania: A Hazard Function Approach. Research working 
paper 4945; The World Bank, Poverty and Inequality Team: Development Research Group

Cherti, M. (2008). Paradoxes of Social Capital: a multi-generationl study of Maroccans in London; IMISCOE Dissertation; Amsterdam University Press

Coleman, J. (1990), Foundations of social theory. Cambridge MA: Harvard University Press

Coleman, J. (1988), 'Social capital in the creation of human capital', American Journal of Sociology 94: pp.95-120.

De Haas, H. (2008). The complex role of migration in shifting rural livelihoods: the case of a Moroccan oasis' in van Naerssen, T., Spaan, E. and Zoomers, A. (eds) Global Migration and Development, New York/London: Routledge

De Hein, H.; (2006). Migration Development: A Theoretical Perspective;

De Waal C. (2005), Albania Today, A Portrait of Post Communist Turbulence; London: The center for Albanian Studies

Engle, L. (2004). The World In Motion; Short Essays on Migration and Gender, Geneva: International Organization for Migration

Fennema, M., \& Tillie, J. (2004). Do Immigrant Policies Matter?Ethnic Civic Communities and Immigrant Policies in Amsterdam, Ličge and Zurich". In R. Penninx

Gould, H. (2001) 'Culture and social capital', in: F. Matarasso (ed) Recognising Culture: a series of briefing papers on culture and development. Stoud: Comedia in partnership with the Department of Canadian Heritage and UNESCO

Jolly, S \& Bridge, H. R, (2005).Gender and Migration, Overview Report, Institute of Development Studies

Lucas, R, (2005). International Migration and Economic Development: Lessons from Low-Income Countries, Edward Elgar Publishing

Mai, N. ( 2001). 'Italy is beautiful': The role of Italian television in the Albanian migratory flow to Italy, in Media and migration: Construction of mobility and difference, edited by R. King, and N. Wood. London: Routledge.

Massey, Douglas S. (1988). "International Migration and Economic Development in Comparative.

Putnam, R. (1993), Making Democracy Work. Civic Traditions in Modern Italy. Princeton: Princeton University Press

Putnam, R. (2000), Bowling alone. The collapse and revival of American community. New York: Simon \& Schuster.

Venturini, A. (2004). Post war migration in Southern Europe 1950-2000. An economic Analysis; UK: Cambridge University Press.

Vullnetari, J. (2012). Albania on the Move: Links between Internal and International Migration; IMISCO Research, Amsterdam University Press 